See discussions, stats, and author profiles for this publication at: https://www.researchgate.net/publication/323059130

\title{
Drowsiness detection system based on eye-closure using a low-cost EMG and ESP8266
}

Conference Paper · November 2017

DOI: 10.1109/CITISEE.2017.8285502

CITATION

4 authors:

Dian Artanto

politeknik mekatronika sanata dharma

3 PUBLICATIONS 1 CITATION

SEE PROFILE

Deradjad Pranowo

Universitas Sanata Dharma

1 PUBLICATION 1 CITATION

SEE PROFILE
READS

306

Muhammad Prayadi Sulistyanto

Politeknik mekatronika Sanata Dharma

1 PUBLICATION 1 CITATION

SEE PROFILE

Ervan Erry Pramesta

Politeknik Mekatronika Sanata Dharma

2 PUBLICATIONS 1 CITATION

SEE PROFILE 


\section{Drowsiness Detection System based on Eye-closure using A Low-Cost EMG and ESP8266}

\author{
Dian Artanto \\ Mekatronika \\ Politeknik Mekatronika \\ Sanata Dharma \\ Yogyakarta, Indonesia \\ dian.artanto@pmsd.ac.id
}

\author{
M. Prayadi Sulistyanto \\ Desain Produk Mekatronika \\ Politeknik Mekatronika \\ Sanata Dharma \\ Yogyakarta, Indonesia \\ prayadi@pmsd.ac.id
}

\author{
Ign. Deradjad Pranowo \\ Mekatronika \\ Politeknik Mekatronika \\ Sanata Dharma \\ Yogyakarta, Indonesia \\ dradjad@pmsd.ac.id
}

\author{
Ervan Erry Pramesta \\ Desain Produk Mekatronika \\ Politeknik Mekatronika \\ Sanata Dharma \\ Yogyakarta, Indonesia \\ ervan@pmsd.ac.id
}

\begin{abstract}
Many accidents are caused by drowsy drivers. To prevent such accidents, it is necessary to create a device that can detect early drowsiness on the driver and immediately wake the driver. From the study it is known that a reliable indicator to measure drowsiness is the average duration of eyelid closure. This paper presents a prototype of drowsiness detection on the driver using a low-cost EMG, called Myoware, which can be used to detect the closure of the eyelid without injuring the eyes, by simply attaching it to the skin around the eyelid. To facilitate this attachment, an eyeglass is used. Furthermore, with the addition of ESP8266, it has been possible to create a drowsiness level detector that can be monitored online via the internet.
\end{abstract}

Keywords-driver drowsiness; eye closure duration; a low-cost EMG; an eyeglass frame; ESP8266.

\section{INTRODUCTION}

Drowsy drivers are a major contributing factor to traffic accidents. It has been proven in many studies, that there is a relationship between drivers who are sleepy with traffic accidents. Preventing the driver from drowsiness will be able to reduce the occurrence of accidents. [1,2].

Drowsy driving is a major contributing factor to a traffic accident. This has been proven by the many studies that found a connection between driver drowsiness and traffic accidents. Preventing the driver from drowsiness will be able to reduce accidents. Physiological measures have frequently been used for drowsiness detection as they can provide a direct and objective measure. Possible measures are EEG (ElectroEncephalo-Graphy), eye movements, eye blink and eyelid closure [3].

EEG is an electrophysiological monitoring method to record electrical activity of the brain. EEG has shown to be a reliable indicator of drowsiness. The amount of activity in different frequency bands can be measured to detect the stage of drowsiness. The disadvantage of using EEG are difficult to measure in field settings due to signal artifact, are not readily amenable to real time signal processing and are not highly predictive of impaired behavior due to drowsiness [4].

Further, instead of using EEG, technological development has enabled more detailed measurement of eyelid movements in real time. Initial reports suggest that the velocity and amplitude of eyelid movements provide useful indicators of drowsiness and that the use of multiple eyelid closure metrics may improve the prediction of drowsiness [5].

Eye movements can be measured using EOG (ElectroOculo-Graphy). EOG is a technique for measuring the corneoretinal standing potential that exists between the front and the back of the human eye. However, just like EEG, EOG has a weakness in the impractical placement of the device and the number of electrodes that must be put on the driver [6].

Eyelid closure can be monitored with the camera very precisely and quickly. However, the use of the camera has a limitation of illumination, as the normal cameras do not work well at night when monitoring is more important. Other concerns for camera-based systems are the high cost and the loss of image when the drivers look in their mirrors outside the view of cameras. In addition, most of the camera-based system need computers, image processing algorithms and feature extraction techniques to extract drowsy symptoms [7].

Instead of the camera, the eyelid closure can be captured using a portable and low-cost device based on IR sensors mounted on an eyeglass, that directing an IR beam to the human eye [8]. However, strong IR beam in high temperature could be harmful to eyes [9].

As an alternative drowsiness detection device, this paper proposes the use of a low-cost EMG (Electro-Myo-Graphy) to monitor the eyelid muscles, and measure the duration of the eyelid closure, then sound a warning when the duration exceed the limit.

\section{METHODS}

\section{A. Prototype of the Detector}

In this paper, as mentioned earlier, a drowsiness detection device is proposed using a low-cost EMG, which is widely available in the local market under the name Myoware. To be able to measure the muscle electrical activity on skin, that has a very small voltage value (in $\mu \mathrm{V}$ unit), Myoware is equipped with 3 electrodes; 2 of them must be placed on skin in the measured muscle area, and 1 electrode must be placed on skin outside the muscle area, which is used as the ground point. All three electrodes can use any conductor material [10] 
2017 2nd International Conferences on Information Technology, Information Systems and Electrical Engineering (ICITISEE), Yogyakarta, Indonesia

The muscle to open and close the eyelids known as Levator Palpebrae, located at the top of the eye. To measure the tension in the muscle, 2 electrodes must be placed around the muscle, precisely in the upper eyelid, while the rest of electrode can be placed outside the muscle, in the area close to the ear. The placement of a pair of EMG electrodes does not need to be pressed, just simply touching the skin. Therefore, the placement of a pair of electrodes can be done with the help of glasses, i.e. by placing it on the frame of the top glasses, such that when the glasses are worn, the pair of electrodes can touch the upper eyelid skin, as shown in Figure 1 below.

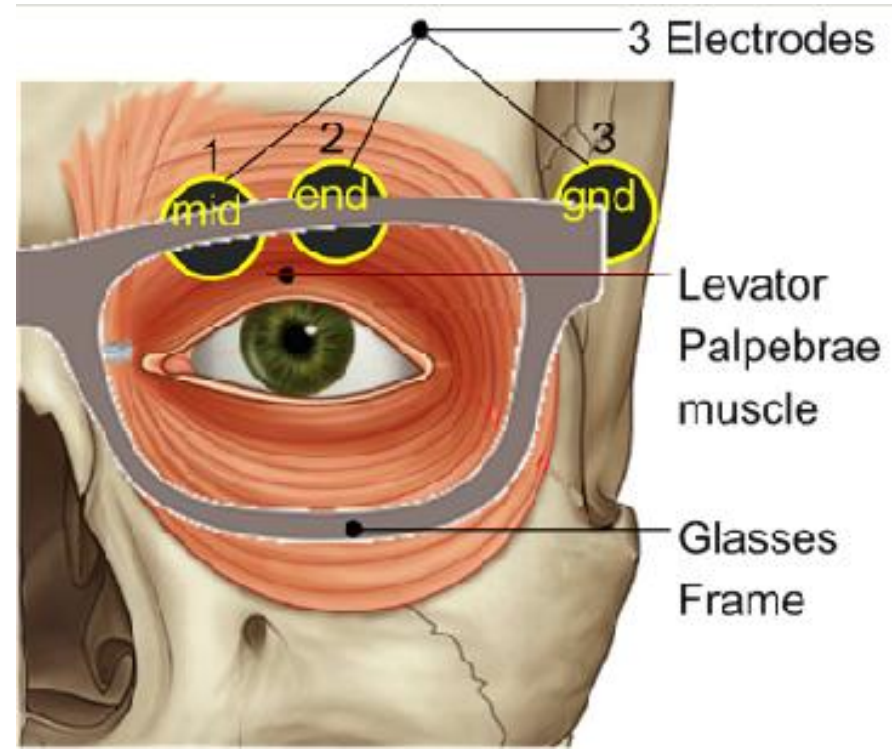

Figure 1. The placement of 3 electrodes on eyeglass frame.

The following figure is a schematic circuit of a Myoware Muscle Sensor [10].
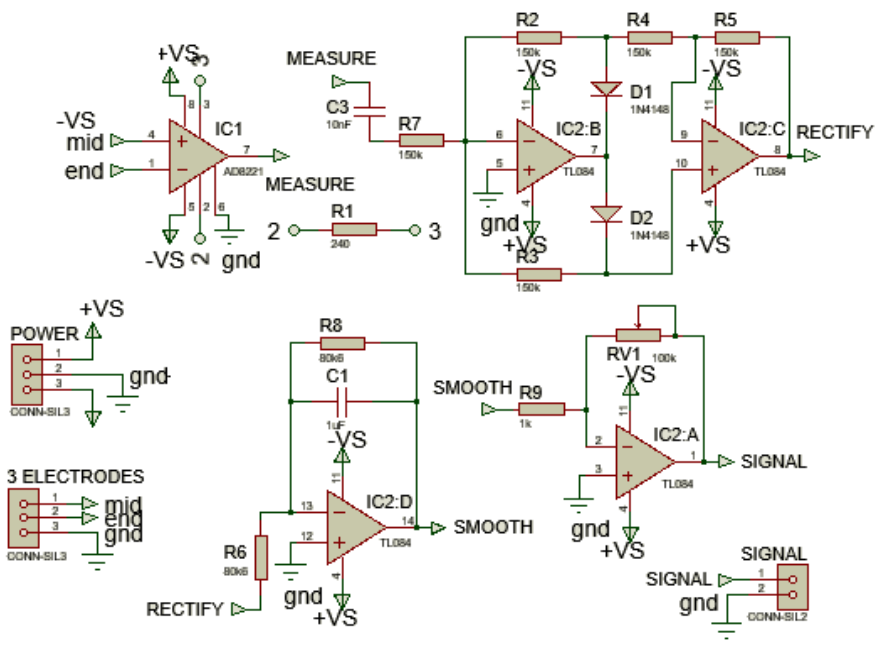

Figure 2. Schematic circuit of Myoware.

Figure 3 and 4 below show the graph of the Myoware output value using Serial Plotter of IDE Arduino, when the eyelids are closed and when the eyelid are opened. It appears that the value of the graph curve becomes greater than 0 when the eyelid is closed, and is 0 when the eyelid is opened.

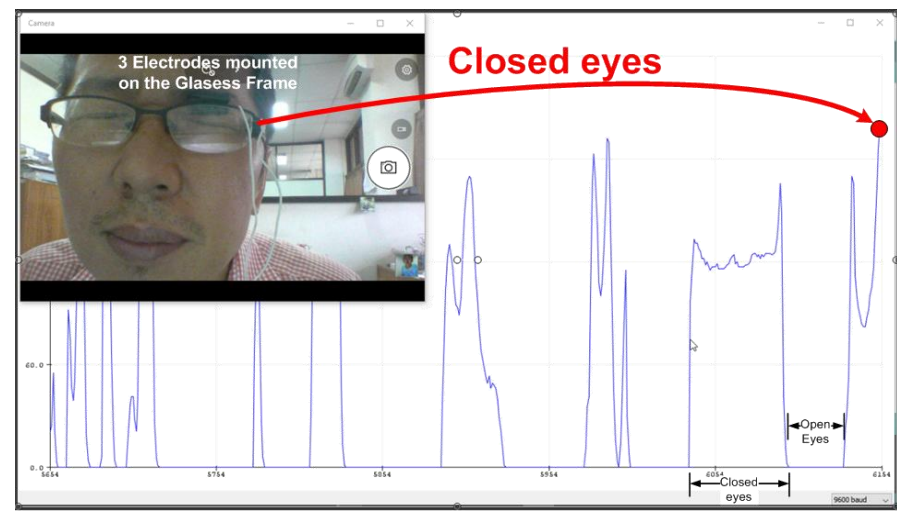

Figure 3. The graph when the eyelid is closed

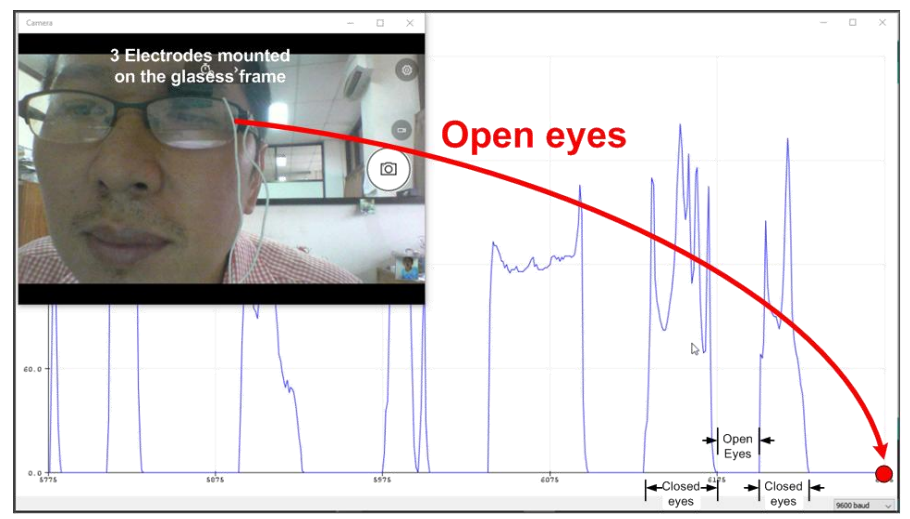

Figure 4. The graph when the eyelid is opened

\section{B. Prototype of the Alert and Monitoring System}

After the Myoware output when the eyelid is opened and closed is known, the next step is to add an alert system so that the device can give a warning when a certain limit value is exceeded. To achieve this, a Buzzer has been added. Besides that, to monitor and record the duration of eyelid closure in real-time, an ESP8266 Wi-Fi module has been added. With the ESP8266, data is sent to the internet wirelessly. Figure 5 below shows the ESP8266 circuit with Buzzer.

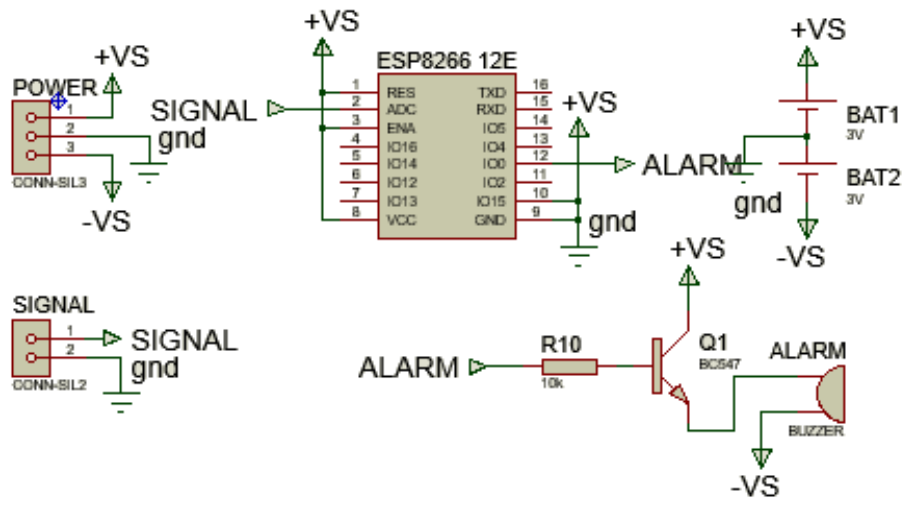

Figure 5. ESP8266 circuit with Buzzer 


\section{Drowsiness level and Google Spreadsheet}

Drowsiness level are calculated based on how many seconds the eyelid is closed, which is accumulated in 1 minute. If the accumulated value in 1 minute is less than 5 , then the drowsiness level is low, whereas if more than 10 , the drowsiness level is high, and buzzer will sound. This level of drowsiness level will be sent to the internet every minute with the help of ESP8266, which is displayed in Google Spreadsheet. The following figure shows a drowsiness level monitoring record displayed in Google Spreadsheet.

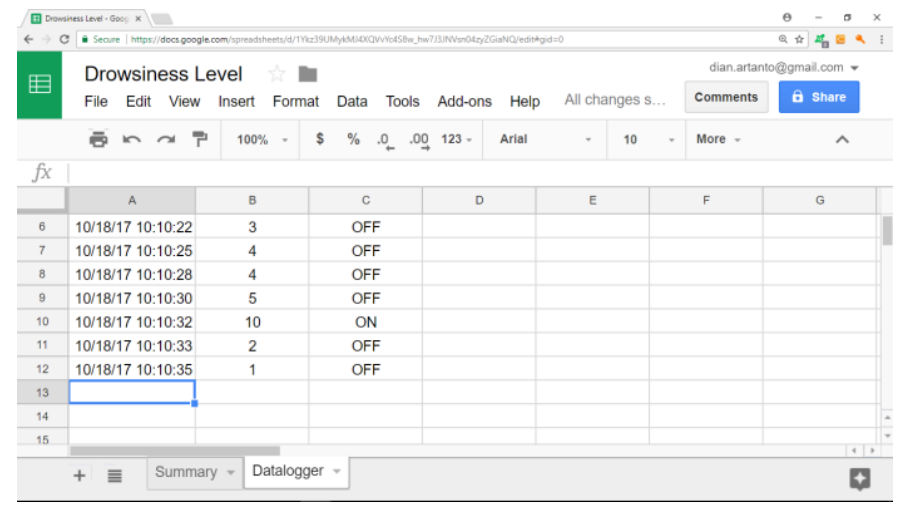

Figure 6. Drowsiness level display on Google Spreadsheet

\section{RESULTS AND DISCUSSION}

\section{A. Results}

From the methods of making the drowsiness detection device, the alert and monitoring system proposed above, has obtained the results of a portable and easily wearable drowsiness detection device that can be monitored online.

Compared to the use of EEG and EOG, the device proposed in this paper is easier to install, because the electrode is installed only 3, so it can be placed on the glasses frame, while in EEG and EOG more than 3, so the use of EEG and EOG is perceived by the driver a little inconvenient, especially for motorcyclists. When compared with the use of cameras to monitor the eyes, the device proposed in this paper is better, because it is not affected lighting, both day and night. When compared to the drowsy detector using an IR beam directed directly to the eye, the device proposed in this paper is better, as it does not injure the eyes.

Another interesting thing, this device is quite economical, because EMG used is a very cheap type of EMG, also the use of ESP8266 makes the monitoring of the drowsiness level can be displayed in google spreadsheet easily. The result of making this tool is quite promising and can be developed to better meet the needs of users.

\section{B. Discussion}

To be discussed, the time limit setting of the accumulation closed eye duration is 10 seconds in 1 minute. The time limit setting is determined by experience and reality on the highway, where for drivers who are driving at high speed, closing the eyes for more than several seconds can lead to a traffic accident.

The time limit value is deliberately made to have variations, due to different needs and levels of drowsiness. Some people have a habit of closing the eyes many times even if not sleepy. Some others may have experienced heavy drowsiness but did not close their eyes at all. So, for some cases, closing the eyes is not directly related to drowsiness. It is necessary to observe the habit before wearing this tool. However, in general, if a person initially rarely closes and blinks, then suddenly over time becomes frequently closed and blinked, then this can be a sign that the person is sleepy. So, a change of pattern from closing the eyes suddenly and often can be a sign that there is drowsiness.

The weakness of this prototype is that the monitoring cannot run in real time, because there is always a time lag when online, that is when data is sent to the internet every minute, the display in Google Spreadsheet will always display a time interval of more than 1 minute.

\section{CONCLUSSION}

In this paper, a prototype of driver drowsiness detection system using a low-cost EMG and ESP8266 wifi module has been proposed. From the observation results, this device is quite promising because of the following points:

1. The use of closed eye duration indicator has a faster detection, because the results are quickly known so that it can give early warning more quickly when the driver is sleepy.

2. Use of EMG is better than EEG and EOG, because the number of EMG electrodes is less, so it is not complicated to be mounted on the glasses frame, and because the drowsiness level can be calculated from the sensor output pulse width without the need for complex data processing.

3. Use of EMG is better than cameras and IR sensors, because it is not affected by daylight or nighttime light, and does not injure the eyes.

4. Use of ESP8266 allows data to be monitored online, accessible easily and recorded, and displayed in Google Spreadsheet, so further research to reduce drowsiness due to sleep disorder or irregular sleep patterns can be done.

Finally, this proposed device has a weakness, i.e. drowsiness detection by monitoring the duration of the closed eyes may be inappropriate, as each person can have different drowsiness behaviors and characteristics. However, when people close their eyes for a long time, in driving conditions, this is obviously very dangerous, even if the person is not sleepy though.

\section{REFERENCES}

[1] R. Zuraida, H. Iridiastadi, and I. Z. Sutalaksan, "Indonesian driver's characteristics associated with road accidents", International Journal of Technology (2017) 2: 311-319, ISSN 2086-9614. 
[2] M. A. Puspasari, E. Muslim, B. N. Moch, and A. Aristides, "Fatigue Measurement in Car Driving activity using Physiological, Cognitive, and Subjective Approaches", International Journal of Technology (2015) 6: 971-975, ISSN 2086-9614.

[3] U. Svensson, "Blink behaviour based drowsiness detection - method development and validation", Master's thesis project in Applied Physics and Electrical Engineering, 2004, Swedish National Road and Transport Research Institute, ISSN 1102-626X.

[4] Wilkinson VE; Jackson ML; Westlake J; Stevens B; Barnes M; Swann P; Rajaratnam SMW; Howard ME. The accuracy of eyelid movement parameters for drowsiness detection. J Clin Sleep Med 2013;9(12):13151324.

[5] Z. Mardi, S.N. Ashtiani, and M. Mikaili, "EEG-based Drowsiness Detection for Safe Driving Using Chaotic Features and Statistical Tests", J Med Signals Sens. 2011 May;1(2):130-7.

[6] I. B. Bandara, "Driver drowsiness detection based on eye blink", Faculty of Enterprise \& Innovation, Buckinghamshire New University, Brunel University, March, 2009.
[7] I. García, S. Bronte, L. M. Bergasa, N. Hernandez, B. Delgado and M. Sevillano, "Vision-based drowsiness detector for a Realistic Driving Simulator", Intelligent Transportation Systems (ITSC), 2010 13th International IEEE Conference on.

[8] J. Ma'touq, J. Al-Nabulsi, A. Al-Kazwini, A. Baniyassien, G. A. Issa1, and H. Mohammad, "Eye blinking-based method for detecting driver drowsiness" J Med Eng Technol, 2014; 38(8): 416-419, (O2014 Informa UK Ltd., ISSN: 0309-1902 (print), 1464-522X (electronic).

[9] D.P. Agrawal, "Embedded Sensor Systems “, 2017, @ Springer Nature Singapore Pte Ltd., ISBN 978-981-10-3037-6.

[10] Advancer Technologies Muscle Sensor v3 user's manual, Available from: http://www.advancertechnologies.com/p/muscle-sensor-v3.html.

[11] A. Niraula, "How to Post Data to Google Sheets Using ESP8266", 2016, Retrieved from: http://embedded-lab.com/blog/post-data-google-sheetsusing-esp8266. 